\title{
Effect of Transition Metal Salicylates on the Degradation of Poly(styrene Peroxide)
}

\author{
K. KISHORE, K. RAVINDRAN, and R. NAGARAJAN, Inorganic and Physical \\ Chemistry Department, Indian Institute of Science, Bangalore-560012, India
}

The metal-catalyzed oxidation of polymers at low temperatures (up to, say, $150^{\circ} \mathrm{C}$ ) and hydrocarbons has been studied by many workers, and the widely accepted mechanism is

$$
\begin{aligned}
& \mathrm{ROOH}+\mathrm{M}^{n+} \rightarrow \mathrm{RO}^{-}+\mathrm{M}^{(n+1)+}+\mathrm{OH}^{-} \\
& \mathrm{ROOH}+\mathrm{M}^{(n+1)+} \rightarrow \mathrm{RO}_{2}+\mathrm{M}^{n+}+\mathrm{H}^{+}
\end{aligned}
$$

However, the above mechanism is not a general one because it depends largely on the specific system under study. In some instances, even desensitization in the oxidation by the metal ions has been reported. ${ }^{1}$ Generally, the ROOH [in eqs. (1) and (2)] represents hydroperoxide which is commonly formed in many polymers during the oxidation. It has been observed that decomposition energy of hydroperoxide is decreased in the presence of metal ions. ${ }^{2,3}$

Polystyrene (PS) oxidation does not yield hydroperoxide, instead in-chain peroxide is formed. ${ }^{4}$ The hydroperoxide formation does not occur in PS because when the labile tertiary $\mathrm{H}$ atom is abstracted, the resulting free radical is well stabilized due to resonance with the benzene ring. In addition, steric hindrance also prevents hydroperoxide formation. Winslow also had pointed out in the discussion session of the paper by Cameron that the isopropyl groups in poly(p-isopropyl)styrene are oxidized readily in the dark at $80^{\circ} \mathrm{C}$, but the - H's of PS are remarkably resistant to oxidation even at $140^{\circ} \mathrm{C}$. All the above evidence go against the possibility of hydroperoxide formation in PS during oxidative degradation. Since in-chain peroxide is formed during the PS oxidation, ${ }^{4}$ the mechanism of metal catalysis of PS oxidation will be understood when it is known how the metal ions interact with the in-chain peroxides.

PS oxidative degradation has been found to be enhanced in the presence of transition metal salicylates. In this article we examine the effect of transition metal salicylates, namely Fe(III), NI(II), Co(II), and Mn(II) salicylates, on the in-chain peroxide of PS, namely, polystyrene peroxide (PSP).

\section{EXPERIMENTAL}

Isothermal thermogravimetry (TG) was done in a simple McBain-type assembly. Shimadzu GC-4CPF gas chromatograph coupled with a Shimadzu PYR-1A pyrolyzer and Chromatopac 2A integrator/plotter/calculator was used. A stainless steel column with a $3-\mathrm{mm}$ i.d. and $3 \mathrm{~m}$ long was filled with Chromosorb 2 (60-80 mesh) coated with dioctylphthalate $(2 \mathrm{wt} \%)$ and was used for the separation of the pyrolyzed products. Ultra-pure $\mathrm{N}_{2}$ was used as a carrier gas and flowed at a constant rate of $40 \mathrm{~mL} / \mathrm{min}$. A programmed heating rate $\left(10^{\circ} \mathrm{C} / \mathrm{min}\right)$ was used for the columns. A column temperature of $110^{\circ} \mathrm{C}$ was used. Sample weights between 0.7 and $1 \mathrm{mg}$ were taken in a platinum boat and introduced into a preset furnace at a given temperature for the pyrolysis. These samples were pyrolyzed for $10 \mathrm{~s}$ before letting them into the column. Pyrolysis of PSP was done at $120^{\circ} \mathrm{C}$. 


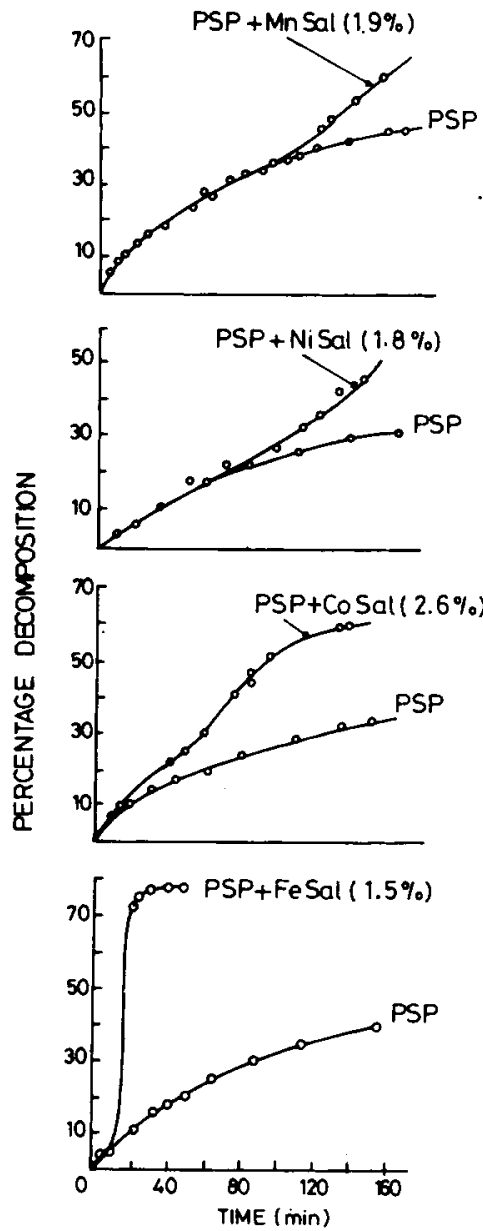

Fig. 1. Isothermal TG curves of PSP containing metal salicylates at $90 \pm 1^{\circ} \mathrm{C}$.

PSP was prepared and characterized as reported earlier. Transition metal salicylates were synthesized and characterized as published elsewhere. Viscous PSP and the metal complex in a fine powder form were mixed thoroughly before the mixture was subjected for experimental study.

\section{RESULTS AND DISCUSSION}

Isothermal TG thermograms of PSP and PSP containing metal salicylates are shown in Figure 1. The sensitization order was found to be as follows: FE $>\mathrm{CO}>$ $\mathrm{NI}>\mathrm{Mn}$. In the case of $\mathrm{Fe}$, the sample decomposed almost instantaneously and hence proper measurements could not be done. But the very fact that the decomposition was so fast shows that $\mathrm{Fe}$ has the maximum effect. The sensitization of PSP degradation in the presence of metal ions can be explained as follows.

The initiation step in PSP is the breakage of $\mathrm{O}-\mathrm{O}$ linkages to produce the macroradicals which subsequently form benzaldehyde and formaldehyde. The metal ions can act in this step to facilitate the breakage of $\mathrm{O}-\mathrm{O}$ bonds. This can happen via the formation of a complex between the peroxy group of PSP and metal ions. Denisova et al. proposed that the complex formation of the metal ions and $\mathrm{O}_{2}$ takes place during oxidation of styrene in the presence of $\mathrm{Co}$ (II) stearate. Other investigators have also proposed similar complex formation between the metal ions with oxygen. 
Since the PSP decomposition occurs in the range of $80-150^{\circ} \mathrm{C}$, it is likely that anhydrous complexes interact with PSP. The ease with which the metal ions complex with the peroxide will determine the rate at which the peroxides degrade. The mechanism could be written in the following manner.

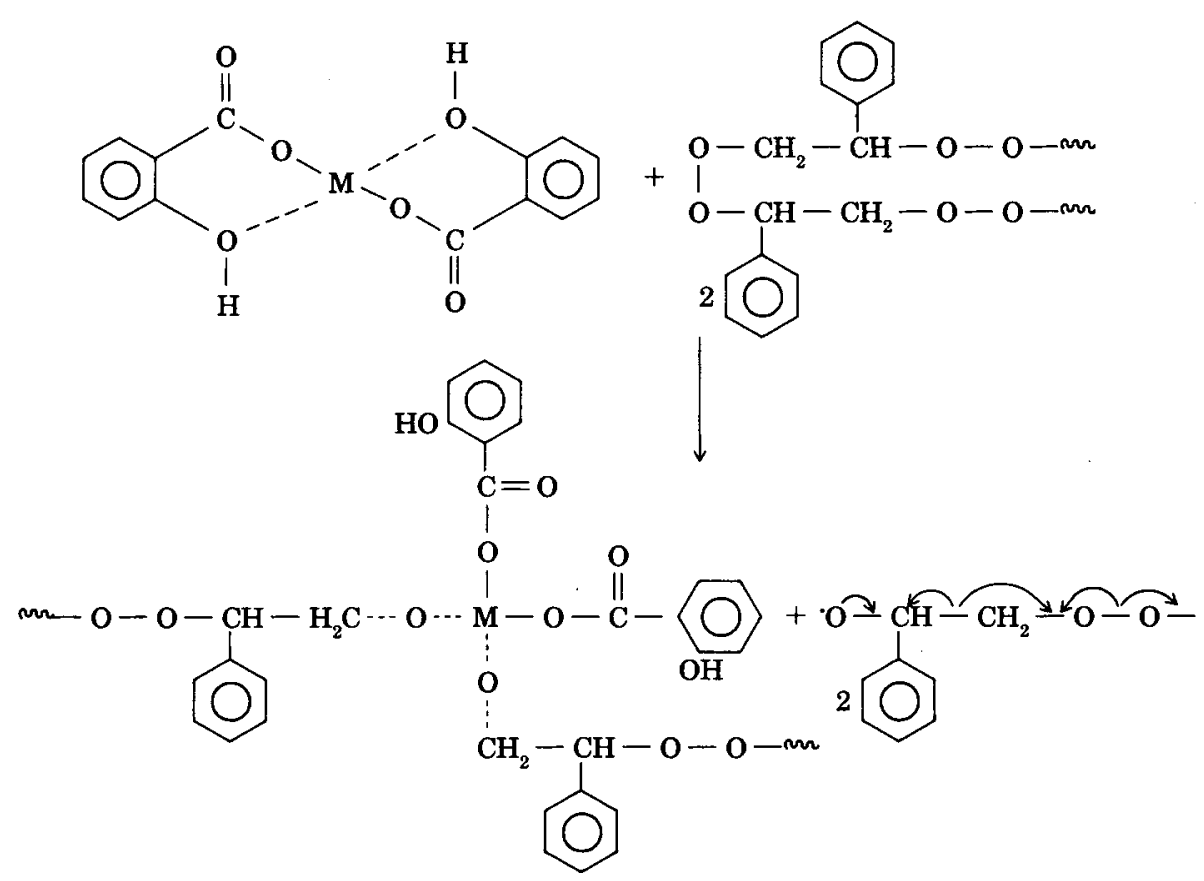

The other possibility of the interaction of metal ions is in the propagation step. If the metal ions interact in the initiation step then the product distribution should not be altered. However, if they interact in the propagation step and also get involved in the reaction with the products of decomposition to enhance the over all rate of degradation then one should observe a change in the product distribution.

The pyrolysis chromatograms of PSP and PSP + various salicylates is shown in Figure 2. That the benzaldehyde peak is broadened and the formaldehyde peak splits into two in the presence of metal ions suggests that there is a definite reaction between the products of decomposition and the metal ions. Bawn et al. have studied the $\mathrm{Co}$ (III)-catalyzed antioxidation of $\mathrm{C}_{6} \mathrm{H}_{5} \mathrm{CHO}$. The rate-determining step has been postulated as

$$
\mathrm{C}_{6} \mathrm{H}_{5} \mathrm{CHO}+\mathrm{Co}^{3+} \rightarrow \mathrm{Co}^{2+}+\mathrm{C}_{6} \mathrm{H}_{5} \mathrm{CO}^{+}+\mathrm{H}^{+}
$$

Thus, the metal ions also can react with the products of decomposition, as a result of which a certain amount of the products are converted to free radicals which can again take part in the propagation reactions. A similar reaction is possible with formaldehyde. Consequent to the above reaction some of the benzaldehyde is destroyed and hence the rate of production of benzaldehyde is decreased. More is seen in the PGC (Fig. 2) where the benzene peak is broadened in the presence of metal ions. Similarly, the chromatogram (Fig. 2) shows splitting of the formaldehyde peak which also suggests that there is some interaction of the metal ions with formaldehyde also. The fact that the product distribution changes shows that the metal ions act in the propagation step. 

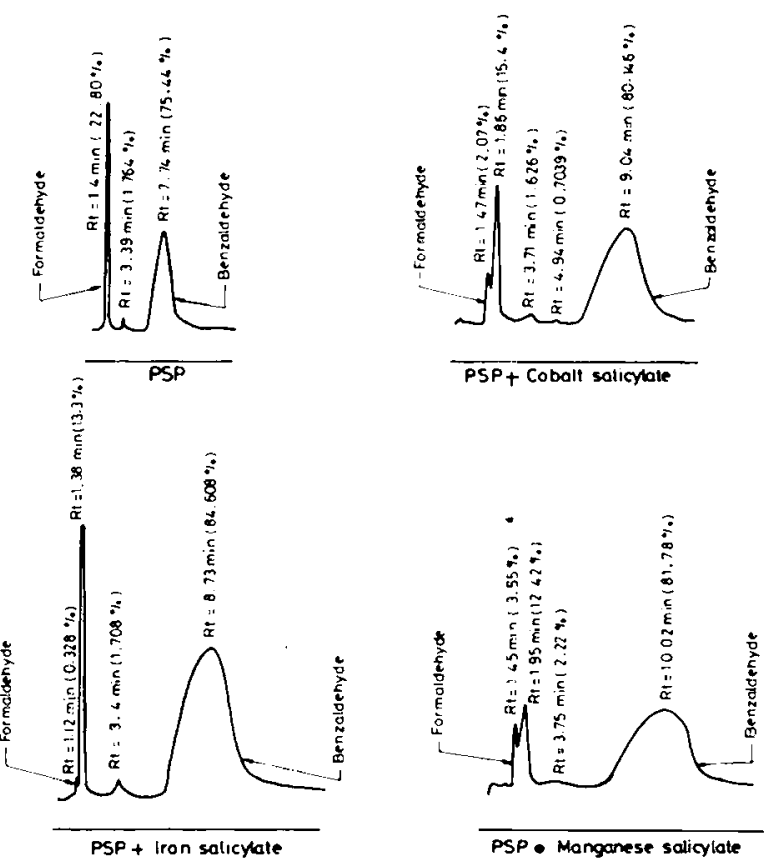

Fig. 2. Gas chromatograms of PSP + metal salicylates (ca. $2 \%$ ) pyrolyzed at $120^{\circ} \mathrm{C}$ (column temperature $=10^{\circ} \mathrm{C}$, column $=$ dioctylphthalate; detector temperature $=190^{\circ} \mathrm{C}$; in jection port temperature $=140^{\circ} \mathrm{C}$ ).

It may be concluded that transition metal salicylates enhance the PSP degradation by reacting with the products of decomposition to produce active radicals which enhance the propagation rate to produce the products at a faster rate.

\section{References}

1. P. George, E. Riedel, and A. Robertson, Proc. R. Soc. London Ser. A, 185, 283 (1946).

2. C. Bawan and J. Sharp, J. Chem. Soc., 1954 (1957).

3. S. H. Goh and K. W. Phang, Thermochim. Acto, 25, 109 (1978).

4. K. Kishore, V. R. Pai Verneker, and V. Gayathri, Fuel, 60, 164 (1981).

Received April 4, 1983

Revised November 18, 1983

Accepted November 29, 1983 